\title{
The Application of Intelligent Prediction Nonlinear PID Control in Nc Position Control
}

\author{
Y. Zhang, Y.G. Gong, L.F. Chen \\ Department of physics and information engineering \\ Jining University \\ Qufu, China
}

\begin{abstract}
According to the moment of inertia and load torque changes in machine tool servo motor position control, proposed intelligent prediction nonlinear PID control algorithm. Nonlinear PID control is used to adjust the proportion, integral, differential coefficients of traditional PID controller in real time. Intelligent prediction algorithm ensures fast convergence when the error is larger, improved tracking capabilities. Simulation results show that a combination of the control strategy has better stability and dynamic tracking accuracy.
\end{abstract}

Keywords-intelligent prediction control; nonlinear PID control; PMSM; NC position control

\section{INTRODUCTION}

Permanent magnet synchronous motor possesses the characteristics of high efficiency and low loss and its control structure generally consists of the current loop, speed loop and position loop. Its control strategy general current loop adopts hysteresis control method, the speed loop PI control law, to ensure that it steady speed control. Position loop usually uses the proportion control law to guarantee high precision and good tracking performance [1]. But because of the speed loop and current loop nonlinear coupling, the rapidity of the system and the anti-jamming ability and robustness to system parameter perturbation are not ideal. In recent years, in order to resolve the problems, a lot of linear and nonlinear control technology is gradually applied in the design of the motor system control [2-5]. Intelligent prediction algorithm with multi-step prediction, rolling optimization and feedback correction control rate, has the merits of operative control effect, strong robustness and the model accuracy requirement is not high.

In this paper, combining the characteristics of the nonlinear PID and intelligent prediction algorithm, design the intelligent prediction nonlinear PID controller. When error is larger, intelligent prediction algorithm make control parameter less and able to online estimate, improve the closed-loop stability and robustness of the system. When the error is less, the nonlinear PID self-adjusting ability makes the operation of the motor to reach the ideal effect. This method is visual, simple control structure, easy to realize.

\section{PERmanent Magnet Synchronous Motor MATHEMATICAL MODEL}

Hypotheses: ignore core saturation effect; air-gap magnetic field for sinusoidal, induction electromotive is sine wave shape; regardless of the hysteresis and eddy current loss; field current without dynamic response; the rotor without exciting winding; $\mathrm{Id}=0$.

Based on the above assumptions, the linear mathematical model in dq coordinate system as follow:

$$
\begin{aligned}
& u_{q}=R i_{q}+L\left(d i_{q} / d t\right)+\omega_{r} \psi_{f} \\
& u_{d}=-\omega_{r} L i_{q} \\
& T_{e m}=1.5 p_{n} \psi_{f} i_{q}=K_{t} i_{q} \\
& T_{e m}=T_{l}+B\left(\omega_{r} / p_{n}\right)+\left(J / p_{n}\right)\left(d \omega_{r} / d t\right)
\end{aligned}
$$

Where, ud and uq are stator voltage in dq coordinate system; id and iq are stator current in dq coordinate system; L is the self inductance of stator winding in $\mathrm{dq}$ coordinate system on; R and $\omega r$ are the stator resistance the electrical angular velocity in dq coordinate system; $\Psi f$ and pn are rotor flux and the number of poles; Tem and $\mathrm{Tl}$ are electromagnetic torque and load torque, $\mathrm{B}$ and $\mathrm{J}$ are damping coefficient and moment of inertia.

\section{Intelligent PREdiction Nonlinear Pid CONTROL}

\section{A. Nonlinear PID Controller Design.}

Nonlinear PID controller is adopted the nonlinear combination of $e, \int e, \dot{e}$ in the traditional PID controller linear interval, algorithm is described as:

$$
\begin{aligned}
k_{p} & =a_{p}+b_{p}\left(1-\operatorname{sech}\left(c_{p} e_{1}\right)\right) \\
k_{d} & =a_{d}+b_{d} /\left(1+c_{d} \exp \left(d_{d} \cdot e_{1}\right)\right) \\
k_{i} & =a_{i} \sec h\left(c_{i} e_{1}\right)
\end{aligned}
$$

\section{B. Intelligent Prediction Controller Design}

Because of the speed loop response much faster than the position response, namely the position loop cut-off frequency is far less than the reciprocal of the time constant of the speed loop, when the control rate is derived, speed loop can be equivalent to a first order inertia link, and the structure of position prediction controller is shown in Figure I 


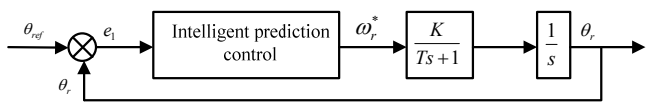

FIGURE I .THE BLOCK DIAGRAM OF POSITION CONTROL SYSTEM.

The prediction control is the control algorithm based on model, and the prediction model has the function of expression system dynamic behaviour in the future for different control strategies are available to calculate the different output prediction trajectory, to select the optimal control strategy to make the system a certain performance optimization.

Rolling optimization way to control the system only on the first increment each time, so the open loop prediction model is:

$$
Y_{m}(k+1)=Y_{0}(k+1)+A \Delta U(k)
$$

Where, $Y_{0}(k+1)$ is the future $\mathrm{P}$ step prediction when no $\Delta \mathrm{u}(k)$ for $\mathrm{k}$ times; $\mathrm{A}$ is the dynamic matrix as A controlled object.

Closed-loop prediction for open loop prediction and feedback correction,

$$
\mathrm{y}_{p}(k+i / k)=y_{m}(k+i / k)+h_{i} e(k), i=1,2,3, \ldots, P
$$

Namely,

$$
\mathrm{y}_{p}(k+i / k)=y_{m}(k+i / k)+h_{i}\left[y(k)-y_{m}(k)\right]
$$

Where, hi is prediction error correction coefficient.

Control algorithm is to determine a set of $M$ control increment, namely

$$
\Delta \mathrm{U}(k)=[\Delta u(k), \Delta u(k+1), \cdots, \Delta u(k+M-1)]^{T}
$$

Acting on the system, make in the future the time length of $\mathrm{P}$ to predict the output value as far as possible close to the desired output.

Take the objective function to minimum for the rolling optimization

$$
J=\|Y r(k+1)-Y p(k+1)\|_{Q}^{2}+\|\Delta U(k)\|_{R}^{2}
$$

Where, $\mathrm{Q}$ is the predicted output error weighting matrix; $\mathrm{R}$ is a null pointer increased weight matrix; $Q \geq 0, R \geq 0$.In the implementation process, only $\Delta \mathrm{u}(k)$ applied to the system, so that,

$$
d^{T}=[1,0,0, \cdots, 0]\left[A^{\mathrm{T}} \mathrm{QA}\right]^{-1} A^{T} Q=\left[d_{1}, d_{2}, \cdots d_{p}\right]
$$

Where, $\mathrm{A}$ is the $\mathrm{P} \times \mathrm{M}$ matrix model; $\mathrm{M}$ is control time length; $\mathrm{P}$ is the biggest forecast time length. $\mathrm{d}^{T}$ can be offline design, can also be online calculation.

$$
\begin{aligned}
& \Delta \mathrm{u}(k)=d^{T}\left[Y_{r}(k+1)-Y_{p}(k+1)\right] \\
& u(k)=u(k-1)+\Delta u(k)
\end{aligned}
$$

From the above analysis can launch the combined controller simplified structure shown in Figure II .

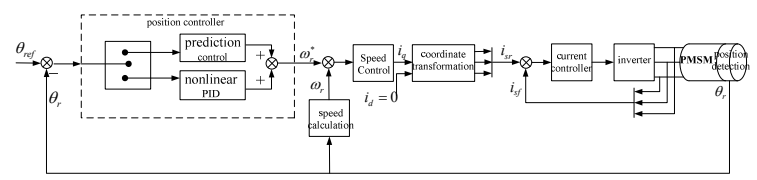

FIGURE II. THE SIMPLIFIED SCHEMATIC DIAGRAM OF COMBINED CONTROL.

\section{SiMULATION EXPERIMENTS}

PID controller and combined controller were designed according to the mathematical model. The main parameters are as follows: the motor and load inertia are $\mathrm{J}=0.00267 \mathrm{~kg} \cdot \mathrm{m} 2$; the friction torque is $4.86 \mathrm{~N} \cdot \mathrm{m}$; disturbance torque is $10 \mathrm{~N} \cdot \mathrm{m}$, electromagnetic torque coefficient is $\mathrm{Kt}=1.11 \mathrm{~N} \cdot \mathrm{m} / \mathrm{A}$; damping coefficient $\mathrm{B}=0.000143 \mathrm{~N} \cdot \mathrm{m} \cdot \mathrm{s}$; the stator resistance $\mathrm{Ra}=2.6 \Omega$; winding inductance $\mathrm{Ld}=\mathrm{Lq}=0.05 \mathrm{H}$;rated current $\mathrm{Ie}=6.4 \mathrm{~A}$; maximum allowable current $\operatorname{Imax}=12.8 \mathrm{~A}$; the number of the magnetic poles are $\mathrm{Pn}=4$; intelligent prediction controller parameters: $\mathrm{N}=100, \mathrm{M}=3, \mathrm{P}=100, \mathrm{Q}=\mathrm{I}, \mathrm{R}=0.1 \mathrm{I}, \mathrm{h}=0.8$; nonlinear PID parameters: $\mathrm{kp}=2.6, \mathrm{ki}=0.86, \mathrm{kd}=0.2$.

\section{(1) Outside interference}

Assuming that applying a step disturbance $30 \mathrm{~N} \cdot \mathrm{m}$ in the first second, the output response curves of position are shown in Figures III and IV. From the figures III and IV tradition PID control has fast rise time, when the load disturbance, the location response curve appeared large offset, and need longer time to recover to a stable position. While using combined control, enhance the capacity of resisting disturbance of the system, to achieve a state of equilibrium time decreases.

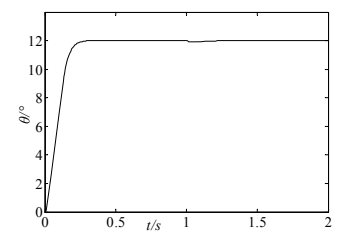

FIGUREIII. RESPONSE CURVE OF COMBINED CONTROL.

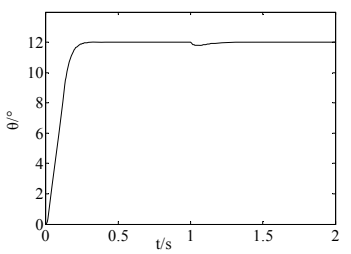

FIGURE IV. RESPONSE CURVES OF TRADITIONAL PID CONTROL.

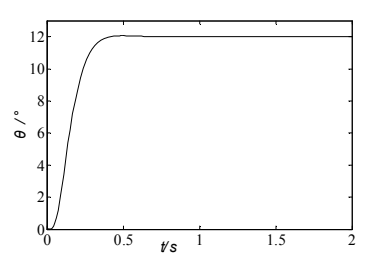

FIGURE V. RESPONSE CURVE OF COMBINED CONTROL. 


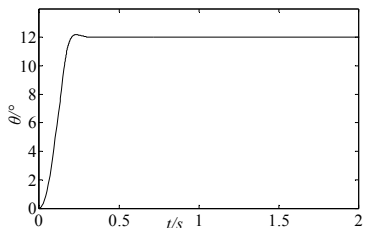

FIGURE VI: RESPONSE CURVES OF TRADITIONAL PID CONTROL.

(2) System parameter perturbation

In order to verify the control effect of system parameters perturbations, assuming that changes in moment of inertia of the system two times. From Figure V and VI, when using the PID control, the system adjusting time becomes longer. In combined control, the response curve of system did not change obviously.

\section{(3) Sine tracking experiments}

The tracking objective function: 10sin (0.7166t), it's tracking error curve shown in Figure VII and Figure VIII. As can be seen from the figure, combined control relative to the traditional PID control has better tracking properties.

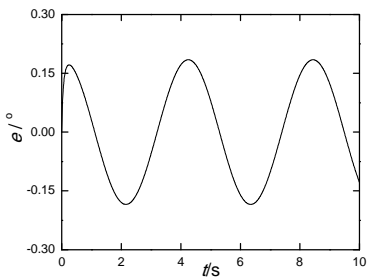

FIGURE VII. ERROR CURVE OF COMBINED CONTROL.

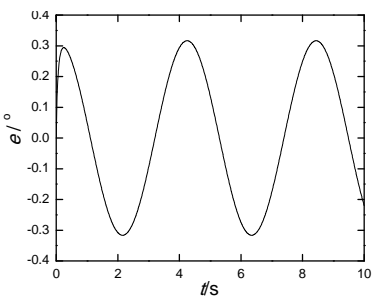

FIGURE VIII. ERROR CURVE OF TRADITIONAL PID CONTROL.

\section{CONCLUSIONS}

According to the large inertia of the machine tool permanent magnet servo system, proposed the combined control strategy of intelligent prediction and nonlinear PID. By nonlinear PID self-tuning capability, adjusting the control parameters to adapt to position changes in system response time, reducing the dependence on human factors. Cases where the error is beyond the set value, through intelligent prediction algorithm allow the system errors quickly converge to within the set value, to ensure that the regulation of nonlinear PID. Simulation results show that, the scheme can adapt to the change of system parameters, can be applied to the machine tool servo system, with high control precision, a quick position response, algorithm is simple in programming.

\section{ACKNOWLEDGEMENT}

The work is supported by the "A Project of Shandong Province Higher Educational Science and Technology Program (J13LB10)".

\section{REFERENCES}

[1] Xu Hongpei, Wu Xinkai, Peng Shuangguang, Research on the intelligent position servo control system based on PMSM. Electric drive automation, 33, pp. 6-10, 2011

[2] Shen Yanxia, Ji Zhicheng, Passivity-Based Fuzzy Sliding-Mode Control System and Experiment Research for Permanent Magnet Synchronous Motors. Journal of System Simulation, 19, pp. 4012-4016, 2007.

[3] Zi Bin, Zhu Zhencai, Wei Mingsheng, Dynamic Modeling and Control on AC Servomechanism. China Mechanical Engineering, 20, pp. 920923, 2009.

[4] Chen Jian, Cheng Guoyang, Experimental Study of High-Performance Position Control in AC Servo Motors. Electric Machines and Control, 41, pp. 1-5, 2014.

[5] Wang Yang, Liu Yongguang, Simulation of PMSM with Vector Control Based on Simulation. Modular Machine Tool\& Automatic Manufacturing Technique, 2, pp. 78-82, 2011. 